\title{
Linguística aplicada e psicologia do trabalho: a contribuição do conceito de atividade reguladora para a clínica da atividade
}

\author{
Anselmo Pereira de Lima ${ }^{1}$ \\ Universidade Tecnológica Federal do Paraná (Pato Branco, PR)
}

\begin{abstract}
Este ensaio está organizado em quatro partes. Na primeira e na segunda, apresento e discuto o modo como Yves Clot, com base em uma conferência de Vygotsky (datada de 1930), se apropria de conceitos provenientes dos estudos da linguagem (especialmente os de linha bakhtiniana) para, ampliando-os, dar conta de estudos da atividade. Em seguida, apresento e explico, em linhas gerais, o modo como eu mesmo - seguindo esse procedimento - desenvolvi o conceito de atividade reguladora, que se constitui como uma contribuição para a clínica da atividade. Na terceira e na quarta parte, demonstro o modo como o conceito de atividade reguladora se aplica tanto à análise de atividades predominantemente linguísticas, quanto de atividades predominantemente não linguísticas por meio de uma reinterpretação crítica de dados provenientes de trabalhos realizados por dois pesquisadores franceses ligados à clínica da atividade.
\end{abstract}

Palavras-chave: Linguagem, Atividade, Regulação, Clínica da atividade.

Applied linguistics and work psychology: the contribution of the regulating activity concept to the clinic of activity

This essay is organized in four parts. In the first and second part, I present and discuss the way Yves Clot, based on one of Vygotsky's conferences (given in 1930), enlarges and makes use of concepts developed in the language studies (specially the bakhtinian ones) in order to carry out activity studies. Afterwards, I present and explain the way I myself, following these procedures, developed the concept of regulating activity, which turns out to be a contribution to the clinic of activity. In the third and fourth part, by means of a critical reinterpretation of the data analyzed by two French researchers associated to the clinic of activity, I demonstrate the way the concept of regulating activity can productively be employed in the analysis of predominantly linguistic or non-linguistic activities.

Keywords: Language, Activity, Regulation, Clinic of activity.

\section{Introdução}

\begin{abstract}
A pós convidarem-me a compor a mesa-redonda cuja temática foi "Linguagem e Trabalho", os organizadores do I Colóquio Internacional de Clínica da Atividade sugeriram que eu, como linguista aplicado, me pronunciasse a respeito da importância da linguagem para a análise da atividade. Essa sugestão muito me agradou, mas é importante ressaltar que, invertendo-se a ordem dos elementos, seria possível dar também - e sem prejuízos para a temática inicialmente proposta - uma palavra sobre a importância da atividade para a análise da linguagem.

Digo isso com a intenção de mostrar, deixar claro e insistir, primeiramente, na ideia de que não há linguagem de um lado e atividade de outro: a linguagem está na atividade e a atividade está na linguagem, pois ambas se encontram amalgamadas e são inseparáveis (Vygotsky, 1934/2001, p. 55; Clot, 1995/1998, p. 143). Digo isso também para mostrar que, de um lado, os estudos da linguagem - ao produzirem conhecimentos sobre a linguagem humana têm uma contribuição fundamental a dar para os estudos da atividade e que, de outro, estes ao produzirem conhecimentos sobre a atividade - têm também uma contribuição não menos importante a dar para os estudos da linguagem.
\end{abstract}


Linguagem e atividade. Atividade e linguagem. Não importa a ordem. Não importa, no texto, qual aparece em primeiro lugar e com letra maiúscula e qual vem em segundo lugar e com letra minúscula. Para os fins que interessam aqui, o fato é que uma não vem antes nem depois da outra. Ambas formam um todo único. $\mathrm{O}$ estudo da linguagem que ignora a atividade perde de vista esse todo. Da mesma forma, o estudo da atividade que ignora a linguagem também perde de vista esse mesmo todo (cf. Lima, 2010, p. 92; Vygotsky, 1934/1997, pp. 51 52). Os dois tipos de estudo devem, portanto, se complementar. Nesse sentido, quando o assunto é clínica da atividade, é necessário que o linguista estudioso da linguagem se faça psicólogo para melhor dar conta da atividade e que o psicólogo estudioso da atividade, por sua vez, se faça linguista para melhor dar conta da linguagem. Isso se faz necessário, inclusive, para que ambos, linguista e psicólogo, possam mais produtivamente dialogar.

Levando todos esses aspectos em conta, este texto está organizado em quatro partes. $\mathrm{Na}$ primeira e na segunda, intituladas respectivamente "Linguagem e atividade, Atividade e linguagem: uma produtiva analogia" e "Dos dados e da analogia linguagem-atividade ao conceito de atividade reguladora", apresento e discuto o modo como Clot (1999/2004), com base em uma conferência de Vygotsky (datada de 1930), se apropria de conceitos provenientes dos estudos da linguagem (especialmente os de linha bakhtiniana) para, ampliando-os, dar conta de estudos da atividade. Em seguida, apresento e explico em linhas gerais o modo como eu mesmo - seguindo esse procedimento - desenvolvi o conceito de atividade reguladora, o qual se constitui como uma contribuição para a clínica da atividade (cf. Clot, 2010a, p. 14).

$\mathrm{Na}$ terceira e na quarta partes, respectivamente intituladas "Atividade reguladora entre conduzir uma entrevista e permitir que o entrevistado a conduza" e "Atividade reguladora entre parar um trem com segurança e pará-lo no horário", demonstro o modo como o conceito de atividade reguladora se aplica tanto à análise de atividades predominantemente linguísticas, quanto de atividades predominantemente não linguísticas. $E$ isso por meio de uma reinterpretação crítica de dados provenientes de trabalhos realizados por dois pesquisadores franceses ligados à clínica da atividade.

Meu objetivo geral, com isso, aceitando e complementando a sugestão dos organizadores do I Colóquio Internacional de Clínica da Atividade, é justamente apresentar e discutir a importância da linguagem para a análise da atividade e da atividade para a análise da linguagem.

\section{Linguagem e atividade, atividade e linguagem: uma produtiva analogia}

Valorizando dessa forma a relação inequívoca existente entre linguagem e atividade e entre linguística e psicologia, e com o objetivo de entrar em uma discussão mais ou menos aprofundada a seu respeito, gostaria de mencionar parte de uma das conferências de Vygotsky, proferida em 1930. Pretendo, por meio disso, discutir a produtividade e os limites de uma analogia existente entre linguagem e atividade, a qual Vygotsky especifica em termos de uma analogia possível entre instrumentos psicológicos e instrumentos de trabalho (ou instrumentos técnicos). Diz o autor:

No comportamento do homem surge uma série de dispositivos artificiais dirigidos para o domínio dos próprios processos psíquicos. Por analogia com a técnica, esses dispositivos podem receber, de pleno direito, a denominação convencional de ferramentas ou instrumentos psicológicos [...]. Essa analogia, como qualquer outra, não pode chegar a suas últimas consequências até a total coincidência de todos os traços dos instrumentos de trabalho. Os instrumentos psicológicos são criações artificiais; estruturalmente, são dispositivos sociais e não orgânicos ou individuais, destinam-se ao domínio dos processos próprios ou alheios, assim como a técnica se destina ao domínio dos processos da natureza. 
Como exemplo de instrumentos psicológicos e de como seus complexos sistemas podem servir a linguagem, as diferentes formas de numeração e cálculo, os dispositivos mneumotécnicos, o simbolismo algébrico, as obras de arte, a escrita, os diagramas, os mapas, os desenhos, todo tipo de signos convencionais etc. (Vygotsky, 1930/2004, pp. 93 94).

Alguém que soube tirar proveito dessa analogia, explorando sua produtividade e respeitando seus limites, foi, sem dúvida, Yves Clot. Podemos observar isso, de modo pontual, na maneira como ele discretamente a interpreta, amplia e aplica à psicologia do trabalho na interface com a linguística (aplicada) ou, se se preferir, com os estudos da linguagem: ${ }^{2}$

Para Bakhtin, o enunciado é portanto uma atividade linguística dirigida. Pensamos, encorajados pelo próprio Bakhtin [...], que a atividade linguística é uma modalidade da atividade humana que pode servir de analisador para todas as outras modalidades dessa atividade, inclusive o trabalho. É por essa razão que falamos de gênero de atividade e não somente de gênero do discurso (Clot, 1999/2004, p. 36).

Mas é preciso desconfiar de comparações [...]. A prudência é portanto indispensável. Mas podemos reter esta ideia: entre os signos da língua e a atividade linguística na troca verbal cotidiana, existe - no curso da ação, na situação de enunciação - a mesma relação bastante complexa existente também na situação profissional, entre os artefatos e as atividades de trabalho que nela se desenvolvem (Clot, 1999/2004, p. 86).

É, portanto, explorando o potencial dessa analogia e, obviamente, respeitando seus limites, que Yves Clot e outros pesquisadores da clínica da atividade trabalham com, por exemplo, os conceitos de atividade dirigida, gênero de atividade e estilo de atividade. Vejamos como eles fazem isso no que diz respeito ao conceito de atividade dirigida:

A atividade de trabalho [...] é triplamente dirigida e não somente de maneira metafórica. Na situação vivenciada, ela não é unicamente dirigida pela conduta do sujeito ou dirigida através do objeto da tarefa, ela é também dirigida aos outros. A atividade de trabalho se dirige a eles depois de ter sido destinatária da atividade deles e antes de sê-lo novamente. Ela é sempre resposta à atividade dos outros, eco de outras atividades. Ela se situa em uma corrente de atividades da qual se constitui como um elo. [...] $O$ trabalho é [...] atividade dirigida pelo sujeito para o objeto e para a atividade dos outros, pela mediação do gênero. É por essa razão que podemos dizer que essa atividade dirigida é a menor unidade da troca social realizada pelo trabalho. A palavra dirigida comporta aqui três sentidos diferentes na mesma significação, indicando com isso as dissonâncias que animam essa "unidade". Propomos, portanto, fazer do conceito de atividade dirigida o conceito que, em psicologia do trabalho, designa a unidade elementar de análise (Clot, 1999/2004, p. 98).

No parágrafo seguinte, Yves Clot revela a fonte dos estudos linguísticos da qual se serve para desenvolver essas reflexões no campo dos estudos da atividade:

Para Bakhtin, semioticista e linguista, compreender a situação de enunciação na troca verbal é se dotar de uma unidade básica para "dissecá-la". Essa unidade é uma arena. É o enunciado, atividade linguística por excelência. Esse autor define o enunciado do locutor como estando ao mesmo tempo voltado para seu objeto e para o enunciado dos outros que se voltam para esse mesmo objeto. Se não nos esquecermos de mencionar que esse enunciado está dedicado igualmente ao próprio locutor, teremos o conceito que Bakhtin utiliza para analisar tanto as conversações cotidianas quanto as enunciações mais elaboradas como os discursos literários, científicos ou administrativos. Para ele, a língua é habitada para dar conta dessa atividade no mundo dos homens. Pelas razões mencionadas anteriormente, podemos escrever que a atividade de trabalho é igualmente voltada

2 Todas as traduções presentes neste artigo são de minha responsabilidade. 
simultaneamente para o objeto imediato da ação e para a atividade dos outros que se voltam para esse mesmo objeto (Clot, 1999/2004, pp. 98-99).

\section{Dos dados e da analogia linguagem-atividade ao conceito de atividade reguladora}

Eu mesmo me propus a seguir esse caminho, explorando a produtividade da já referida analogia, mas sempre respeitando seus limites. Ao ler e refletir sobre a obra Pensamento e linguagem, de Vygotsky (1934/1997, 1934/2001), meus dados de pesquisa, nos quais eu havia identificado alguns fenômenos que me chamaram muito a atenção, me levaram a me perguntar se para além de uma "linguagem egocêntrica" não haveria também o que eu inicialmente denominava "atividade egocêntrica". Como meu foco era a função reguladora da linguagem e como o termo "egocêntrica" suscitava muitas críticas, especialmente de meus colegas linguistas, passei a me referir aos fenômenos identificados em meus dados como "atividade reguladora", expressão que - de imediato - passou a ser aceita pela comunidade tanto de linguistas quanto de psicólogos.

Minha ideia era, e é, que, assim como a linguagem, em seu processo de ser apropriada ou internalizada pelo sujeito, passa por uma fase intermediária chamada por Vygotsky (1934/1997, 1934/2001), ao menos provisoriamente, "linguagem egocêntrica"; também a atividade passa por esse mesmo processo, ao qual denominei "atividade reguladora". Explicar o que quero dizer com esse conceito em poucos parágrafos não é tarefa fácil. Foi preciso redigir toda uma tese para isso (cf. Lima, 2008), a qual foi publicada recentemente na forma de livro (cf. Lima, 2010). Apesar disso, vou tentar explicá-lo aqui, em linhas gerais. Em seguida, procurarei fazer sua aplicação e demonstração em dados provenientes de estudos de dois pesquisadores franceses ligados à clínica da atividade.

Vygotsky (1934/1997, pp. 96-97) diz que é no momento em que a atividade do sujeito esbarra em uma dificuldade que a linguagem se manifesta, externa ou internamente, com função reguladora. Isso para permitir ao sujeito tomar consciência do obstáculo ou dificuldade no qual esbarrou e, com isso, traçar um plano de superação desse obstáculo ou dificuldade.

A atividade reguladora consiste, justamente, no todo desse processo. Uma vez que linguagem e atividade se encontram amalgamadas (Vygotsky, 1934/2001, p. 55; Clot, 1995/1998, p. 143), ela corresponde ao quadro englobante e, contraditoriamente, englobado, no qual se manifesta a linguagem com essa função reguladora específica. No que diz respeito à atividade de trabalho, especialmente, mas não só, cada gesto profissional do sujeito trabalhador dá conta, ao mesmo tempo, de diversos aspectos operacionais. Isso quer dizer que o sujeito trabalhador, quando realiza um gesto, acaba executando várias tarefas ao mesmo tempo (Lima, 2010, pp. 222-223). Seu gesto profissional acaba se constituindo, na realidade, como o resultado de um compromisso estabelecido ao longo do tempo de sua experiência profissional entre esses vários aspectos operacionais, os quais se revelam contraditórios entre si. Clot (cf. 2010 b, p. 21, p. 61, p. 103) expressaria isso em termos de "conflito de critérios" e diria, provavelmente, baseando-se em Bakhtin (1924/2003), que o gesto profissional vai surgindo e ressurgindo como resultado da resolução sempre provisória e contínua desse conflito.

Cabe aqui, entretanto, uma ressalva: nem todo gesto profissional realiza várias tarefas ao mesmo tempo ou dá conta ao mesmo tempo de diversos aspectos operacionais: o gesto do aprendiz, do novato, do inexperiente, perde de vista algumas coisas, perde de vista alguns aspectos operacionais que - inicialmente perdidos de vista - se apresentam em seguida justamente como os obstáculos ou dificuldades nas quais esbarra a atividade do trabalhador, nas quais - mais especificamente - esbarram seus gestos (Lima, 2010, p. 222). 
Nesse momento, o sujeito trabalhador, por meio da linguagem, toma consciência dos aspectos operacionais que inicialmente perdeu de vista e, com isso, concebe um novo gesto, num esforço de também dar conta desses aspectos operacionais a princípio ignorados (Lima, 2010, p. 223).

Trata-se aqui de uma atividade de regulação do gesto profissional que consiste em um esforço do sujeito para torná-lo tão adequado a uma dada situação de trabalho quanto possível, manifestando-se na forma de uma oscilação constante do sujeito no privilégio, em seu gesto ou em seus gestos, de uns aspectos operacionais em detrimento de outros, até que finalmente consegue estabelecer entre eles um relativo compromisso.

No princípio, essa oscilação é de grande amplitude, podendo ser facilmente identificada, pois se manifesta na forma de uma visível falta de jeito, como diria Bakhtin (1979/2003, p. 284), ou maladresse, como diria Wallon (1959). Conforme avança o desenvolvimento do sujeito trabalhador, isto é, conforme aumenta sua experiência profissional, essa oscilação vai se tornando gradualmente mais discreta, até que parece desaparecer (Lima, 2010, pp. 208-209).

Em outras palavras, o sujeito trabalhador passa, progressivamente, ao longo do tempo, da falta de jeito ou maladresse à maestria em sua atividade, como mostrará a seguir - com particular clareza - a reinterpretação crítica que faço dos dados analisados por Daniel Faïta em um de seus artigos e dos dados sobre os quais Gabriel Fernandez trabalhou para desenvolver sua tese de doutorado na clínica da atividade, em Paris. Isso permitirá verificar que o fenômeno de atividade reguladora consiste, em termos vygotskyanos, no crescimento para dentro da atividade exterior e, em termos bakhtinianos, no próprio desenvolvimento dos gêneros, tanto de discurso quanto de atividade, e em sua apropriação pelo sujeito.

\section{Atividade reguladora entre conduzir uma entrevista e permitir que o entrevistado a conduza ${ }^{3}$}

Segundo Faïta (1995), a intervenção realizada nas empresas por especialistas e consultores externos tende a se tornar cada vez mais frequente, uma vez que se colocam problemas complexos, geralmente ligados a mudanças no sistema produtivo. Nesse processo, a palavra dos trabalhadores, "enquanto modo de acesso privilegiado a uma realidade na maioria das vezes opaca”, é fortemente solicitada (Faïta, 1995, pp. 77-78). É, portanto, pelo diálogo entre especialista e operador, no contexto de uma intervenção específica, que Faïta se interessa em seu texto. Que intervenção é essa?

As sucessivas fases de modernização das fábricas pertencentes a um dado grupo da indústria do cimento trouxe certas consequências, entre as quais estavam algumas mudanças organizacionais que consistiram na introdução de novos sistemas e objetos técnicos de produção, o que levou à eliminação de alguns postos de trabalho. Nesse contexto, o conteúdo do trabalho do operador de controle da produção se constituiu como objeto de polêmicas, pois a direção da empresa, baseando-se em argumentos técnicos, considerava que a função desse operador havia se tornado praticamente inútil, podendo ser suprimida, uma vez que havia sido introduzido na empresa um sistema automático de supervisão da produção.

Os envolvidos e os sindicatos, em resposta aos argumentos da direção da empresa, afirmavam que a redução da equipe faria com que aumentasse a carga de trabalho dos operadores que permanecessem. Como uma tentativa de resolver esse impasse, foi solicitada a

3 Trata-se aqui de um trecho ligeiramente adaptado do texto de minha tese de doutorado (cf. Lima, 2008, pp. 239-243; Lima, 2010, pp. 244-247). 
intervenção de especialistas para o estudo da situação. A primeira fase da ação dos especialistas consistiu em observar a atividade do operador no contexto do processo produtivo. Desse modo, os especialistas, com a colaboração de um operador, passaram a ter um ponto de vista próprio sobre a atividade da fábrica, sobretudo no que se refere ao controle da produção. "Foi nessas circunstâncias," diz Faïta, "e no contexto de um conjunto de entrevistas em uma sala (mas sempre nas dependências da fábrica) que se passou ao aprofundamento da análise por meio da solicitação do ponto de vista dos atores" (Faïta, 1995, pp. 86-87).

O autor toma para sua análise "um fragmento de entrevista dentre outros", o qual é apresentado em anexo a seu texto. Em sua análise, o autor apresenta dois níveis de leitura desses dados, um primeiro intitulado "o conflito de gêneros" e um segundo intitulado "os lugares discursivos e sua evolução".

No primeiro nível de leitura, observa-se que o especialista é aquele que normalmente toma a iniciativa, o que manifesta, ao mesmo tempo, sua adesão ao papel social que lhe cabe (o de alguém que conduz a entrevista e que, portanto, deve questionar o outro) e seu conhecimento do processo técnico-organizacional. Nessa situação, o operador não tem outra escolha a não ser aceitar a regra implícita e aderir, por sua vez, ao papel daquele que responde às perguntas que lhe são feitas, descrevendo o processo produtivo com um máximo de referência à situação concreta de trabalho (Faïta, 1995, p. 87).

Deve-se ressaltar, além disso, que, na fase inicial da entrevista, há estabilidade do gênero de discurso por meio do qual se expressam os dois interlocutores: "em função de um contrato inicial manifestamente claro, o especialista argumenta, isto é, apresenta de modo geral o objeto descrito pelo operador em referência à situação concreta e transforma em questionamento aquilo que é afirmado por seu interlocutor": o especialista pergunta e o operador responde imediatamente à pergunta, havendo alternância constante entre pergunta e resposta. De acordo com o autor, essa estabilidade inicial do gênero de discurso faz com que seja notada de modo muito claro a "ruptura" genérica que ocorre a partir de certo ponto do diálogo: continuando no mesmo gênero, o especialista avança em sua argumentação ao introduzir e questionar o entrevistado por meio de uma categoria analítica denominada "carga de trabalho" (Faïta, 1995, p. 88).

As marcas discursivas provenientes da continuidade do diálogo mostram uma clara transformação genérica: o operador não mais responde às perguntas do especialista, antes continua desenvolvendo seu enunciado. Não há mais, portanto, a alternância constante entre pergunta e resposta: o especialista pergunta e não obtém as respostas de seu entrevistado. Além disso, "a escolha das palavras efetuada pelo operador [...] se torna fonte de conflito argumentativo, materializado pela negação daquilo que ele mesmo afirmou" assim que o especialista tenta transformar essa afirmação em pergunta (Faïta, 1995, p. 88).

A conclusão de Faïta é que o especialista deixou que aparecesse o aspecto privilegiado de seu procedimento discursivo: a partir do funcionamento da interação e de seu domínio do objeto da entrevista, tentou impor seu próprio universo de pensamento ao operador: para o especialista, "a mudança técnico-organizacional se traduz na forma de uma elevação na carga de trabalho". Não lhe restando nada mais que apenas acompanhar o operador em sua "enumeração referencial" da sucessão das ações de produção, o especialista "abandona provisoriamente suas prerrogativas sobre o domínio do diálogo". Ao fim dessa primeira fase, diz Faïta, há uma pausa tão longa (23 segundos) que "justifica a hipótese de uma busca pelo especialista de uma solução adaptada ao impasse no qual se encontra" (Faïta, 1995, pp. 88-89). Isso se passa, provavelmente, no terreno do discurso interior com função reguladora.

No segundo nível de leitura, intitulado "os lugares discursivos e sua evolução", o autor julga possível tirar algumas conclusões mais profundas sobre esses dados. $\mathrm{O}$ operador "ocupou, desde o começo, o lugar daquele que conhece por experiência a realidade que está descrevendo", enquanto o especialista "jogou primeiro o jogo de perguntas-respostas e de 
reformulações progressivas [...]", transformando-se, posteriormente, "naquele que busca fazer evoluir o diálogo fora da relação dos gêneros inicialmente escolhidos, talvez porque a referência sistemática do operador às evidências do trabalho não lhe pareçam propícias ao conhecimento daquilo que não se vê" (Faïta, 1995, p. 89).

De acordo com a hipótese de Faïta, o operador é resistente à tentativa do especialista por correr o risco de se tornar, além daquele que conhece por experiência o trabalho da fábrica, alguém que "fornece aos outros aberturas sobre essa experiência para ser dela desapropriado por um modo de categorização ao qual não tem acesso" (Faïta, 1995, p. 89).

Diante da resistência na qual esbarra, o especialista, lançando o operador no campo da narrativa, procura um meio de reocupar o lugar daquele que conduz a entrevista. Entretanto, inicialmente, isso não parece mudar muita coisa, pois o operador continua com a mesma postura. Até que ocorre uma nova "ruptura" genérica: o operador responde tardiamente à questão do especialista sobre a "carga de trabalho", mas o faz em termos de "sobrecarga de trabalho" (Faïta, 1995, p. 90).

Verifica-se, então, que o operador passa a um gênero discursivo até o momento empregado apenas pelo especialista: no campo da argumentação, é ele que agora "manipula as categorias analíticas e generalizantes": "carga", "sobrecarga" e "condições de trabalho". Observa-se, além disso, que "após a crise sobrevinda no meio do percurso", o diálogo foi retomado, mas em condições e com lugares discursivos diferentes: "o especialista é menos aquele que sabe conduzir e analisar, o operador é menos aquele que oferece sua vivência" (Faïta, 1995, p. 91). Para Faïta,

o operador, sem dúvidas, forneceu a seu interlocutor, sem exprimi-lo por enunciados identificáveis como tais, mas por meio de seu comportamento discursivo, indicações para a redefinição do contrato inicial. Coube, então, ao especialista repensar sua posição, recolocar em questão o método e o ferramental, engajar-se na renegociação dos princípios da cooperação" (1995, p. 92).

Verifica-se que o especialista oscila entre dois extremos contraditórios: 1) o daquele que conduz a entrevista e analisa o que é dito pelo entrevistado sobre sua experiência; e 2) o daquele que dá espaço para que o próprio entrevistado conduza a entrevista e analise o que diz sobre sua própria experiência. Trata-se, como diz Faïta (1995, p. 93), de um processo de "reintegração do sujeito em um debate que o implica, como sujeito de sua própria experiência ao mesmo tempo que como sujeito de seu discurso".

$\mathrm{O}$ autor refere-se, finalmente, à necessidade de criar as condições para a produção de uma fala autêntica sobre o trabalho, evitando o emprego de normas estranhas a esse objeto, que poderiam traí-lo. Em seguida, afirma que "um domínio diferente da dimensão da linguagem pelo especialista" poderia contribuir para a superação desse obstáculo (Faïta, 1995, p. 93). A oscilação do especialista entre os dois extremos contraditórios apontados há pouco é uma marca da manifestação da atividade reguladora, a qual, no próprio processo de enfrentamento do referido obstáculo, vai progressivamente conduzindo o especialista a esse domínio diferente da linguagem: um gesto discursivo adequado à situação. 


\section{Atividade reguladora entre parar um trem com segurança e pará-lo no horário ${ }^{4}$}

De maneira geral, Fernandez (2004) trata do processo de desenvolvimento do gesto profissional de frenagem de um condutor de trem na Gare du Nord, de Paris. Esse condutor de trem, na ocasião de uma sessão de autoconfrontação cruzada, lança o seguinte desafio a seus pares, outros condutores de trem: "eu desafio vocês a encontrar um maquinista que consiga fazer uma parada no fim da plataforma da Gare du Nord com um único golpe de freio". Segundo ele, se um condutor de trem disser que já conseguiu e que consegue frear o trem com um único golpe de freio na Gare du Nord, não passa de "um mentiroso" (Fernandez, 2004, pp. 78-80).

Dois meses mais tarde, esse mesmo condutor de trem se encontra na cabine de condução como tutor de um jovem aprendiz. Depois que esse último já havia conduzido um pouco, coube ao condutor reassumir a condução do trem. Ao chegar à Gare du Nord, ele para o trem puxando a alavanca de freio apenas uma vez. $\mathrm{O}$ aprendiz percebe o feito de seu tutor e o aplaude. "Ele consegue", diz Fernandez, "executar a frenagem que ele havia dito dois meses antes ser impossível de realizar" (2004, p. 82). Para o pesquisador, há "uma ligação entre a situação de autoconfrontação cruzada vivenciada dois meses antes e a consecução de um gesto até então considerado impossível" (Fernandez, 2004, p. 82). Diz o autor:

A arte da frenagem consiste em obter permanentemente a velocidade ideal do trem em função de numerosas coerções [...]. A velocidade limite regulamentar para passar pelo último sinal é de $60 \mathrm{~km} / \mathrm{h}$. Entretanto, a velocidade real na qual passam muitos condutores resulta de um compromisso entre tendências opostas. De um lado, quanto menos elevada for a velocidade, menor é o risco de acidente em caso de parada de urgência. De outro, uma velocidade elevada possui duas vantagens: 1) ela permite respeitar o horário previsto para o trem, o que, além de ser um elemento da segurança, responde igualmente aos imperativos comerciais de regularidade; 2) ela evita atrasar os colegas na partida, que não podem partir antes da liberação das agulhas pelo comboio que está chegando (Fernandez, 2004, pp. 66-67, itálicos e negritos adicionados).

\section{Diz, ainda:}

Ao chegar à entrada da plataforma, os maquinistas devem então dar conta de duas coerções suplementares. Por um lado, devem antecipar as limitações que serão impostas, alguns metros adiante, a liberação dos crocodilos a $20 \mathrm{~km} / \mathrm{h}$ e depois $10 \mathrm{~km} / \mathrm{h}$. Logicamente, o mais simples é frear bruscamente nesse local para baixar rapidamente a velocidade e, depois, se entregar à força da inércia. Mas, por outro lado, devem também se esforçar por liberar rapidamente as agulhas para não atrapalhar os colegas que esperam para partir [...]. A velocidade adotada resulta, portanto, de um compromisso e, na maioria das vezes, nesse local, ela é de $40 \mathrm{~km} / \mathrm{h}$ [...]. "É necessário, portanto, chegar nem rápido demais nem devagar demais" (Fernandez, 2004, pp. 66-67, itálicos e negritos adicionados). ${ }^{5}$

O grupo de profissionais com o qual o pesquisador conduziu sua intervenção clínica se constituiu de cinco condutores de trem. Por ordem decrescente de experiência, eles têm 30, 25, 15, 7 e 1 ano de prática na condução de trens (Fernandez, 2004, pp. 14-15). ${ }^{6}$ O pesquisador filmou a parada desses cinco maquinistas na Gare du Nord e constatou que cada um deles freia

\footnotetext{
4 Trata-se aqui também de um trecho ligeiramente adaptado do texto de minha tese de doutorado (cf. Lima, 2008, pp. 243-249; Lima, 2010, pp. 248-253).

5 Os termos "crocodilo" e "agulhas" são definidos com ilustrações na versão francesa do site da Wikipédia. Ver "crocodile signalisation" e "aiguillage” em www.wikipedia.org.
}

6 A referência a cada um desses condutores de trem será feita por meio da menção de sua quantidade de anos de experiência entre parênteses. 
o trem de uma maneira diferente: há, portanto, "cinco realizações diferentes do mesmo gesto de frenagem" (Fernandez, 2004, p. 69).

Para frear o trem, de um certo ponto de referência comum aos cinco condutores ao ponto de parada, há 900 metros a percorrer. $\mathrm{O}$ mais rápido dos condutores, com 30 anos de experiência, percorreu essa distância em 1 minuto e 23 segundos, enquanto o mais lento, com 1 ano de experiência, a percorreu em 1 minuto e 33 segundos. Os cinco condutores, para começar a frear, baseiam-se no mesmo ponto de referência. Para frear é preciso puxar a alavanca de freio.

O condutor mais jovem (1), cuja parada é a mais longa, está a $30 \mathrm{~km} / \mathrm{h}$ no início da plataforma e, por causa disso, perde alguns segundos: "ele prefere privilegiar a segurança ao horário", ele "aperta o mais precocemente", ele "realiza a depressão mais clara" (Fernandez, 2004, p. 69).

Seus colegas $(30,25,15$ e 7) dão um primeiro aperto menos forte e, depois, procuram modular fazendo gestos repetidos de empurrar e puxar a alavanca de freio, com amplitude moderada, a fim de realizar uma desaceleração bem mais progressiva. Ao chegar à marquise, agem novamente sobre a alavanca de freio por meio de uma série de apertos e desapertos [...]. Dentre esses quatro condutores experientes, os três mais antigos no métier (30, 25 e 15) executam numerosos pequenos gestos para desacelerar bem progressivamente. $\mathrm{O}$ menos antigo dentre eles (7) puxa a alavanca de freio mais bruscamente, com isso assemelhando-se mais ao mais jovem dos cinco (1), mas modula rapidamente seu gesto com a ajuda de três pequenos gestos de desaperto para ajustar a desaceleração, com isso assemelhando-se mais aos três condutores mais velhos (30, 25 e 15) [...]. O mais jovem maquinista (1) termina com o desaperto do freio [...]. Seus quatro colegas $(30,25,15$ e 7$)$, por sua vez, chegando um pouco mais rapidamente, devem terminar apertando um pouco, puxando, portanto, bem levemente (Fernandez, 2004, p. 68-69, itálicos adicionados).

Para o autor, "podem-se classificar esses condutores $(30,25,15,7$ e 1 ) em três categorias": 1) "o menos experiente (1) faz menos gestos, mas puxa mais bruscamente, realizando um aperto mais forte"; 2) "o segundo condutor menos experiente (7) realiza uma frenagem intermediária. Como o mais jovem (1), ele puxa bruscamente no primeiro aperto, enquanto, como os mais antigos $(30,25$ e 15), modula muito rapidamente essa primeira ação, de modo que, quanto ao tempo de frenagem, se assemelha aos antigos (30, 25 e 15)"; 3) "os antigos (30, 25 e 15) fazem numerosos gestos de amplitude moderada, permitindo obter uma curva de parada regular" (Fernandez, 2004, p. 69).

Para Fernandez, trata-se de um gesto de frenagem que

circula entre os membros do coletivo de trabalho e que [...] permite realizações diferentes por condutores diferentes, mas também [...] pelo mesmo condutor (30), de um momento a outro de sua carreira. É por isso que, mesmo que na sequência desta pesquisa nós nos atenhamos a acompanhar o desenvolvimento desse gesto em um condutor, ficaremos atentos para nunca perdermos de vista a dimensão transpessoal que cada realização pessoal do gesto contém nela mesma (Fernandez, 2004, p. 71, itálicos adicionados).

A propósito desses dados, cabe fazer algumas perguntas que o pesquisador, apesar de seu material de análise as sugerirem, parece não ter se colocado e que, consequentemente, parece ter acabado por não responder: 1) qual é a relação entre o nível de experiência de cada condutor e sua maneira de frear, ou seja, seu gesto de frenagem?; 2) do ponto de vista do desenvolvimento do gesto, qual é a relação entre as cinco realizações diferentes do mesmo gesto de frenagem?; 3) a classificação desses cinco condutores (30, 25, 15, 7 e 1) em três 
categorias, uma vez que há uma "dimensão transpessoal" em cada execução diferente do gesto de frenagem, ${ }^{7}$ não significaria que há, em uma sequência, três fases progressivas de desenvolvimento de um único e mesmo gesto?

Não se pretende responder aqui longamente a essas perguntas. O leitor terá notado que as respostas são nelas sugeridas: há, de fato, uma relação de progressão entre o nível de experiência de cada condutor e sua maneira de frear, de modo que os diferentes gestos de frenagem correspondem efetivamente a três fases sequenciais e progressivas do processo de desenvolvimento de um único e mesmo gesto ao longo do tempo de experiência de um condutor, qualquer que seja, na mesma situação de trabalho.

É inevitável notar que o jovem condutor de trem (1) não consegue estabelecer, mesmo após um ano de experiência - na situação de frenagem na Gare du Nord - um compromisso entre a segurança, de um lado, e o horário, de outro. $\mathrm{O}$ jovem condutor começa a executar a ação privilegiando, isto é, concentrando-se sobre uma das coerções (aspectos operacionais) da atividade entre outras que ele precisa gerenciar ao mesmo tempo, em simultaneidade. Mas há uma segunda coerção (aspecto operacional) que se apresenta e se impõe ao que eles procuram fazer inicialmente e lhes complica a atividade: o jovem condutor de trens começa pela segurança e, pouco depois, se dá conta ${ }^{8}$ de que não poderá se concentrar unicamente nela, descobre que deverá gerenciar o horário ao mesmo tempo que a segurança.

Entre a segurança e o horário, o jovem condutor de trem oscila. Essa oscilação, que desempenha uma função reguladora da atividade, se manifesta materialmente no exterior, podendo ser identificada e analisada. No caso do jovem condutor (1), parece que essa oscilação ainda não começou a acontecer marcadamente, apegado que ele está à segurança, mas, provavelmente, começará a ocorrer mais tarde. Pode-se identificar essa oscilação com maior clareza, entre os cinco condutores, por exemplo, no comportamento daquele que tem sete anos de experiência: "como o mais jovem (1), ele puxa bruscamente no primeiro aperto, enquanto, como os mais antigos (30, 25 e 15), modula muito rapidamente essa primeira ação, de modo que, quanto ao tempo de frenagem, se assemelha aos antigos (30, 25 e 15)" (Fernandez, 2004, p. 69, itálico adicionado).

Esse condutor, assim que "puxa bruscamente no primeiro aperto", começa se concentrando na segurança, mas, imediatamente, se dá conta de que não poderá se concentrar isoladamente na segurança; ele "se lembra" de que deve também gerenciar o horário ao mesmo tempo que a segurança e, então, oscila: "modula muito rapidamente essa primeira ação". Segundo Fernandez (2004, p. 68), essa modulação consiste em "gestos repetidos de empurrar e puxar a alavanca de freio, com amplitude moderada, a fim de realizar uma desaceleração bem mais progressiva".

Em que consiste precisamente a oscilação desse condutor (7)? Em um movimento de aproximação entre a segurança, de um lado, e o horário, de outro: ele está muito próximo de conseguir dar conta dessas duas coerções contraditórias (aspectos operacionais) ao mesmo tempo, está muito próximo do curto-circuito (Vygotsky, 1925/2001, p. 174, p. 270) que dá acabamento ao gesto. Quando ele aperta o freio, acaba fazendo-o além da medida, assim privilegiando mais a segurança do que o horário (o trem, pela ação do sistema de frenagem, avançará menos rapidamente, haverá mais segurança). Para compensar esse excesso, ele desaperta o freio, assim privilegiando o horário (o trem, pela ação menos severa do sistema de frenagem, não reduzirá muito a velocidade, haverá menor atraso).

\footnotetext{
7 Com esse terceiro questionamento e pelas observações a seguir, fica evidente que o pesquisador parece ter perdido de vista justamente aquilo que ele se propunha a nunca deixar de considerar: "a dimensão transpessoal que cada realização pessoal do gesto contém nela mesma”.

8 "Dar-se conta" significa "tomar consciência". Como não há tomada de consciência sem a mediação da linguagem (Vygotsky, 1934/1997, 1934/2001), fica evidenciado em casos como esse o papel fundamental desempenhado pelo discurso na atividade, seja de modo interior ou exterior.
} 
Mas, ao desapertar o freio, termina por desapertá-lo além da medida, assim privilegiando mais o horário que a segurança. Cada aperto e cada desaperto repete o fenômeno: ora o condutor privilegia a segurança em detrimento do horário, ora privilegia o horário em detrimento da segurança. Em outras palavras, essa "série de apertos e desapertos" corresponde à micro-oscilações contínuas do condutor, entre o privilégio da segurança e o privilégio do horário, um em detrimento do outro. Trata-se aqui de um caso típico de manifestação do fenômeno de atividade reguladora.

Os condutores de trem mais experientes $(30,25,15$ e 7) não dão conta do polo segurança e do polo horário ao mesmo tempo, antes oscilam entre um e outro. Essa oscilação corresponde a uma atividade de regulação do gesto de frenagem. Os condutores experientes oscilam também ora da segurança para o horário, ora do horário para a segurança. Os condutores experientes oscilam, portanto, de um extremo a outro, procurando, com isso, conciliá-los em simultaneidade: na situação de frenagem na Gare du Nord, deve-se, como diz Fernandez (2004, p. 67), "chegar nem rápido demais nem devagar demais".

É preciso admitir que "fazer uma parada no fim da plataforma da Gare du Nord com um único golpe de freio" (Fernandez, 2004, pp. 78-80) corresponde a algo extremamente difícil e complexo. A intervenção clínica conduzida pelo pesquisador parece ter, é verdade, o grande mérito de ter impulsionado um dos condutores mais experientes a realizar aquilo que inicialmente ele mesmo considerava impossível: houve, de fato, um curto-circuito (Vygotsky, 1925/2001, p. 174, p. 270) entre as duas "tendências opostas" (segurança e horário) e o gesto profissional teve seu acabamento, seu parachèvement, como diria Clot (1999/2004, pp. 199. 216).

O pesquisador provavelmente tem razão quando diz que há "uma ligação entre a situação de autoconfrontação cruzada vivenciada dois meses antes e a consecução de um gesto até então considerado impossível" (2004, p. 82). Parece que a intervenção clínica realmente levou esse condutor a prestar mais atenção a suas possibilidades ainda não realizadas e a tentar realizá-las. Como diz Bernstein (1996, p. 185), a atenção inteligente pode acelerar consideravelmente o desenvolvimento.

Em outras palavras, no âmbito da clínica da atividade, por meio dos procedimentos de autoconfrontação cruzada, o mérito da intervenção conduzida por Fernandez (2004) parece ser, entre outros, o de ter levado esse condutor de trem mais experiente a fazer uso de sua atenção inteligente. Entretanto, a pesquisa, apesar de tratar do desenvolvimento de um gesto técnico ou profissional, não parece ter conseguido explicar suficiente e satisfatoriamente como e por que esse gesto se desenvolve.

O conceito de atividade reguladora permite, como se pode verificar, que se lance um olhar diferenciado sobre os dados primorosamente descritos pelo pesquisador. Mas estes também permitem que se lance um olhar diferenciado sobre o próprio fenômeno de atividade reguladora, o qual é constitutivo de toda atividade, especialmente de trabalho: as oscilações reguladoras podem avançar apenas até certo ponto, nele "estagnando", o que leva - nesse caso - a "uma repetição da ação de modo idêntico, sem desenvolvimento, sem superação efetiva das dificuldades encontradas no curso da atividade" (Lima, 2010, p. 237). Isso faz com que se configure um "defeito de repetição" que se metamorfoseia em "repetição do defeito", havendo o "subdesenvolvimento" do gesto profissional e, consequentemente, da própria atividade (Clot, 2008, pp. 158-159).

Podemos dizer, portanto, que os procedimentos da clínica da atividade servem, entre outras coisas, para isso: recolocar em movimento a atividade reguladora constitutiva de toda atividade de trabalho que se encontre, de alguma forma, estagnada, levando os sujeitos trabalhadores a se superarem, isto é, como foi o caso do condutor de trem, a irem além de si mesmos, ainda que isso lhes pareça impossível. Nesse sentido, o desenvolvimento do conceito de atividade reguladora, baseado em dados concretos e na analogia existente entre linguagem e 
atividade, se constitui, como diz Clot (2010a, p. 14), como uma dupla contribuição: "para a análise do gesto profissional em sua gênese social e pessoal" e "para a clínica da atividade que tentamos desenvolver".

\section{Breves considerações finais}

Gostaria de concluir esse texto enfatizando a produtividade da analogia inicialmente proposta por Vygotsky entre os instrumentos psicológicos e os instrumentos técnicos e, portanto, entre linguagem e atividade. Gostaria também de enfatizar que a analogia tem seus limites. Não me parece, entretanto, que ela tenha sido explorada até esse ponto, isto é, até seus limites. Importa estudar a linguagem para compreender a atividade, mas também, e ao mesmo tempo, estudar a atividade para compreender a linguagem. Tarefa nada fácil, mas necessária, pois linguagem e atividade se interpenetram e se interdefinem.

No quadro da clínica da atividade, os estudos da linguagem e da atividade só têm a ganhar, portanto, se, em uma parceria dialógica, o linguista - sem deixar de ser linguista - se fizer psicólogo e este - sem deixar de ser psicólogo - se fizer linguista.

\section{Referências}

Bakhtin, M. (1979/2003). Estética da criação verbal (4⿳亠丷a ed., Paulo Bezerra, trad.). São Paulo: Martins Fontes.

Bakhtin, M. (1924/2003). Pour une philosophie de l'acte (Ghislaine Capogna Bardet, trad.). Lausanne:L'Age d'Homme.

Clot, Y. (2010a). Prefácio/Préface. In A. P. Lima (Org.), Visitas técnicas: interação escola-empresa. São Paulo: CRV.

Clot, Y. (2010b). Le travail à coeur: pour en finir avec les risques psychosociaux. Paris: La Découverte.

Clot, Y. (2008). Travail et pouvoir d'agir. Paris: Puf.

Clot, Y. (1999/2004). La fonction psychologique du travail (4ª ed). Paris: Puf.

Clot, Y. (1995/1998). Le travail sans l'homme? (2ª ed). Paris: La Découverte.

Faïta, D. (1995). Dialogue entre expert et opérateur: contribution à la connaissance de l'activité par l'analyse des pratiques langagières. Connexions, 65, 77-97.

Fernandez, G. (2004). Développement d'un geste technique: histoire du frenage en Gare du Nord. Tese de Doutorado em Psicologia do Trabalho, Conservatoire National des Arts et Métiers, Paris, França.

Lima, A. P. (2010). Visitas técnicas: interação escola-empresa. São Paulo: CRV.

Lima, A. P. (2008). Visitas técnicas: um processo de conciliação escola-empresa. Tese de Doutorado em Linguística Aplicada e Estudos da Linguagem, Pontifícia Universidade Católica de São Paulo, São Paulo.

Vygotsky, L. S. (2001). A construção do pensamento e da linguagem (Paulo Bezerra, trad.). São Paulo: Martins Fontes.

Vygotsky, L. S. (1934/1997). Pensée et langage (3ª ed., Françoise Sève, trad.). Paris: La Dispute.

Vygotsky, L. S. (1930/2004). O método instrumental em psicologia. In Teoria e método em psicologia (pp. 93-101, Claudia Berliner, trad.). São Paulo: Martins Fontes.

Vygotsky, L. S. (1925/2001). Psicologia da arte (Paulo Bezerra, trad.). São Paulo: Martins Fontes.

Wallon, H. (1959). La maladresse. Enfance, 4 (12), 264-276.

Endereço para correspondência

selmolima@hotmail.com
Recebido em: 22/08/2012

Aprovado em: 06/12/2012 